\title{
The history of botulinum toxin in Brazil
}

\author{
A história da toxina botulínica no Brasil \\ Carlos R. Souza-Dias ${ }^{1,2}$ (D) \\ 1. Faculdade de Ciências Médicas, Irmandade da Santa Casa de Misericórdia de São Paulo, São Paulo, SP, Brazil. \\ 2. Instituto Strabos, São Paulo, SP, Brazil.
}

Botulinum toxin is a neurotoxin produced by the bacteria Clostridium botulinum and has always been considered a lethal poison that is acquired via the consumption of contaminated food, such as meat, fish, or pickled vegetables. There are seven different serotypes of botulinum toxin, labeled A, B1, C, D, E, F, and G. This investigation focuses on type A botulinum toxin, as most strains of this type retain their toxigenicity well, yield highly potent culture fluids ( $\geq 1$ million lethal doses per milliliter of culture fluid), and can easily crystallize in stable form.

The German poet and physician Justinus Andreas Christian Kerner (1786-1862) attended patients with paralysis after ingestion of chorizo. He perceived that the chorizo contained a poison that he termed the "poison of chorizo." He suggested that that toxin could be used therapeutically in certain muscles. At the beginning of the 20th century, the microorganism responsible for the paralysis was identified as a bacterium, which was named Clostridium botulinum (probably based on the Greek word klostér [kloster], which means fuse, and the Latin term botulus, which means chorizo). At the end of the 1960s, Alan B. Scott, an ophthalmologist and senior investigator of the Smith-Kettlewell Eye Research Institute of San Francisco, California, began to study the therapeutic use of botulinum toxin as part of an in-

Submitted for publication: July 15, 2021

Accepted for publication: October 5, 2021

Funding: This study received no specific financial support.

Disclosure of potential conflicts of interest: The author does not have any

potential conflicts of interest to disclose.

Corresponding author: Carlos R. Souza-Dias.

E-mail: carlosrsdias32@gmail.com vestigation for a substance with a lasting but reversible paretic effect for the treatment of infantile strabismus ${ }^{(1)}$. He began his studies in monkeys and then in other animals. He tried some substances, such as alcohol, anesthetics of prolonged action, and snake neurotoxin, until he found type A botulinum, which he named Oculinum. His clinical studies with that substance began in 1977 (Figure 1).

In $1988^{(2)}$, Scott started applying Oculinum to human extraocular muscles for the treatment of strabismus and nystagmus, in addition to the human lid muscle for retraction and blepharospasms. In 1988, the laboratory Allergan bought the rights of the product and later changed its name to Botox (Figure 2).

In view of the need for a profound investigation of the toxin before use in human patients, by exigency of the Food and Drug Administration, Scott named investigators in some countries to increase the statistics of treated patients. In 1981, I was honored with this indication (Figure 3).

At the beginning, Oculinum was provided to me in San Francisco. I stored it in a Styrofoam box, because it must be kept frozen. The first shipment of the vials was accompanied by an electromyograph and special needles for the injections. Later on, I started receiving the toxin by mail (Figure 4). Each vial contained 250 units to be dissolved in saline solution, according to the desired degree of solution.

For me, at the beginning, it was an investigation, as I had no experience, and the pertinent bibliography was very scarce. I began injecting the toxin in the horizontal recti muscles of patients with esotropia or exotropia in my clinic and in the Santa Casa Hospital of São Paulo, where I was the head of the Ophthalmology Department. I always conducted electro-oculography to observe the degree of the force reduction of the injected muscle (Figure 5). 


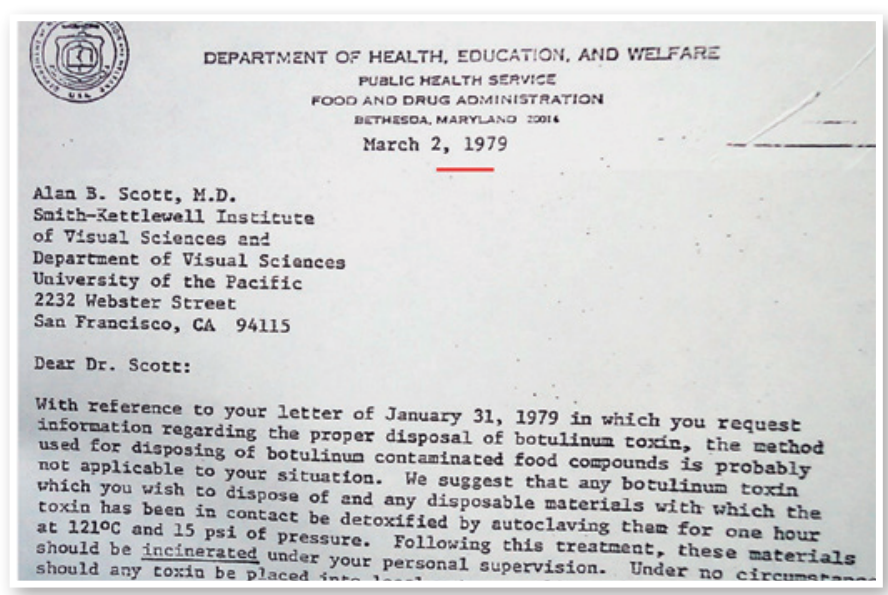

Figure 1. Letter (March 2, 1979) from the Department of Health, Education and Welfare, United States, to Alan B. Scott, about what to do with the contained by botulinum toxin.

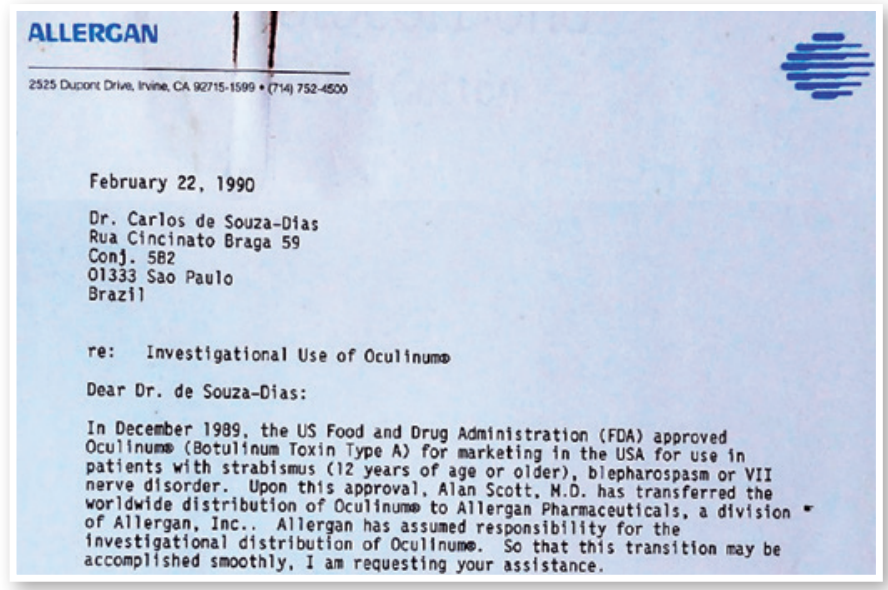

Figure 2. Letter from Allergan to Carlos de Souza-Dias asking for the safety and efficacy data I had collected thus far during my Oculinum treatments.

\section{DRUG IN.JECTION OF EXTRAOCULAR MUSCLEE}

Guidelines of Qualifications for Investigators, Other Than the Sponsor, Alan B. Scott, M. D.

1. Be a board-certified opthalmologist (or equivalent, if in Canada or elsewhere outside the USA).

2. Be affiliated with a recognized university, laboratory, or hospital.

3. Have admitting privileges at a general hospital which can provide full nursing and emergency care.

EQUIPMENT REQUIREMENTS FOR INVESTIGATORS

1) Electromyographic amplifier (EMG) with audio output. Visual display (oscilloscope tube face) or direct write-out is not needed. (Available from Sponsor-Investigator)

2) Injection Needles. $27 \mathrm{ga}, 1-1 / 2$ inch stainless steel hypodermic needles with a recording wire cemented in the bore. (Available from Sponsor-Investigator)

Figure 3. Letter from Alan B. Scott with guidelines of qualifications for investigators, other than the sponsor, and a list of equipment requirements for investigators.

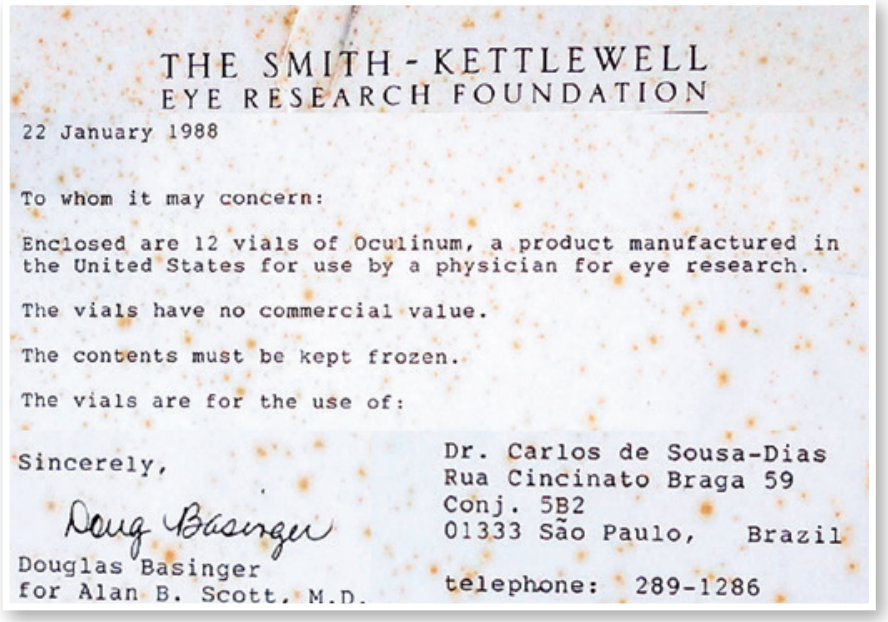

Figure 4. Letter from the Smith-Kettlewell Eye Research Foundation to Carlos de Souza Dias, dated January 22, 1988, together with 12 vials of Oculinum.
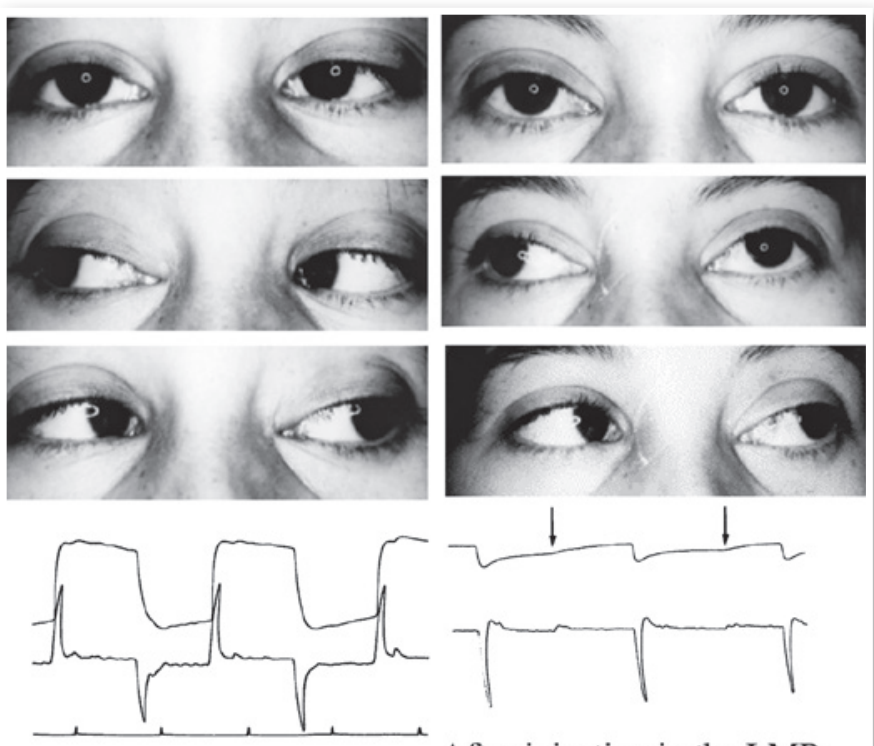

Preinjection

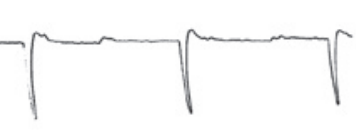

After injection in the LMR

Figure 5. Above, photography of a boy before and after injection of Botulinum in his left medial rectus; it is clear it is muscle paralysis. Lower panels: Electro-oculography before and after Oculinum injection. The images show the reduction in the amplitude and velocity of adduction of the left eye.

l diluted each vial in $2 \mathrm{ml}$ of saline solution and injected between 0.1 and $0.25 \mathrm{ml}$ each time, which corresponds to 1 and $2.5 \mathrm{U}$ (Figures 6 and 7). Here, I present the details of 6 of my first 44 injected patients, which thus represent the first cases in Brazil. 
BOTULINUM A TOXIN FOR EYE MUSCLE INJECTION

\section{PROTOCOL}

PATIENT SELECTION

A. Only patients who would otherwise require strabismus surgery will be considered for toxin injections.

B. $18-80$ years of age

C. Informed consent will be obtained after thorough discussion.

BOTULINUM TOXIN INJECTION - CHILDREN

patient weight according to the following formula:

Patient's weight $\times 6.25 \times 10^{-5}$ micrograms $70 \mathrm{~kg}$

Figure 6. Protocol for Botulinum toxin injection in the eye muscles of patients.

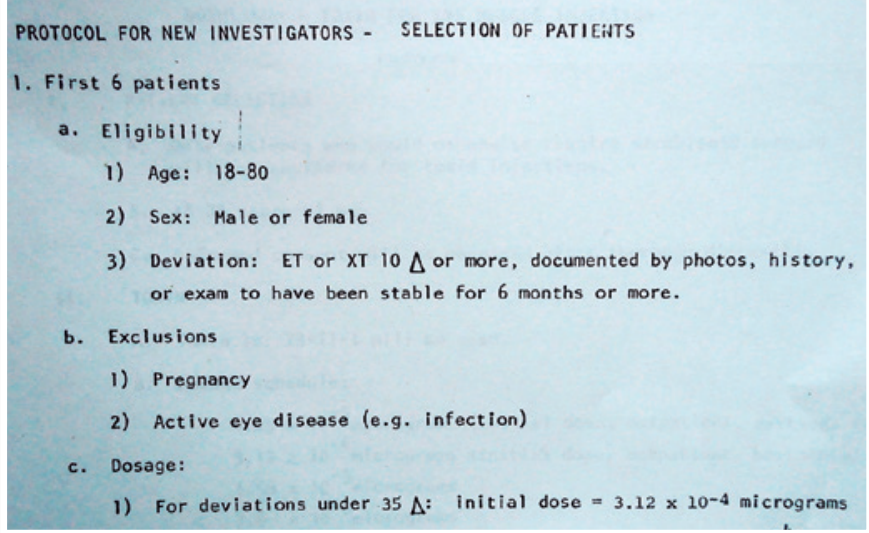

Figure 7. Protocol for new investigators: selection of patients.

\section{CASE 1}

November 15, 1981: A.P., female, 18 years old. The patient had undergone four surgeries for strabismus treatment.

Visual acuity: Both eyes (OU) 20/20.

- Ocular motility:XT 45 $5^{\mathrm{D}}$ RHT $7^{\mathrm{D}}$.

- XT 35 $5^{\mathrm{R}} \mathrm{RHT}^{\mathrm{D}}$.

- XT 32 $2^{\mathrm{D}} \mathrm{RT} 7^{\mathrm{D}}$; MR OU -2.

November 18, 1981: The patient underwent surgery in OU for LR recession (RLR was $11 \mathrm{~mm}$ and RLR was $9 \mathrm{~mm}$ from the limbus).

March 26, 1982: XT 30 ${ }^{\mathrm{D}}$ RHT $6^{\mathrm{D}}$.

March 26, 1982: $0.1 \mathrm{ml}$ of botulinum was injected in the RLR.

March 30, 1982: XT 10 ${ }^{\text {D }}$ RHT 6 ${ }^{\text {D }}$ s slight blepharoptosis

May 19, 1982: XT 13 ${ }^{\text {RHT }} 8^{\text {D. }}$
October 4, 1982: Oculinum was reinjected in the LLR. October 4, 1982: XT4 ${ }^{\mathrm{D}}$ RHT 8$^{\mathrm{D}}$; esthetically well.

February 4, 1984: XT 17 ${ }^{\mathrm{D}}$ RHT $12^{\mathrm{D}}$ without anysotropia.

\section{CASE 2}

October 24, 1981: A.F.D., female, 16 years old. retinal detachment of the right eye at 6 years of age.

Visual acuity: Right eye (OD) null and left eye (OS) 0.4 with -16 sph.

Ocular motility: XT 32 ${ }^{\mathrm{D}}$ RHT $12^{\mathrm{D}}$ without anysotropia.

October 24, 1981: $0.1 \mathrm{ml}$ Oculinum was injected in the RLR.

November 4, 1981: XT 15 ${ }^{\mathrm{D}}$ RHT $12^{\mathrm{D}}$.

December 12, 1981: XT 20 RHT 12 .

March 3, 1982: Surgery: RLR recession $6 \mathrm{~mm}$ and RMR resection $5 \mathrm{~mm}$ with inferior transposition $5 \mathrm{~mm}$.

September 15, 1982: Ortotropia.

\section{CASE 3}

October 24, 1981: S.A.S., female, 20 year old, poor sight in left eye.

Visual acuity: OD 0.9 and OS anisometropic ambliopia with eccentric fixation.

Ocular motility:

- ET $45^{\mathrm{D}}$

- ET $40^{\mathrm{D}}$

- ET 50

October 24, 1981: Oculinum was injected in the LMR; eccentric fixation.

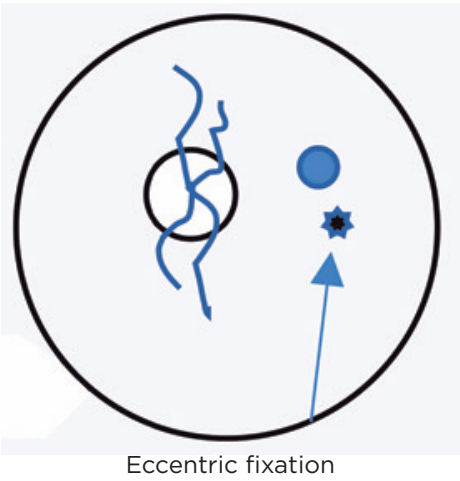

November 11, 1981: No effect; Oculinum was reinjected.

November 27, 1981: XT 15 RLR -4 .

Lost for examination.

Among my 44 cases, 14 experienced blepharoptosis. In the beginning, I used the toxin only for correcting correction strabismus, but later on, I started to use it for the treatment of blepharospasm and facial distony ${ }^{(3)}$, 
after I heard Scott's presentation about it at the meeting of the International Strabismological Association held in Rome in 1986 (Figures 8 and 9).

\section{CASE 4}

March 7, 1988: S.D.M., 57 years old, male. Four years prior, after the death of his sister-in-law, his left inferior lid started to shake, but he soon began to experience half-face contractions.

Diagnosis: Left hemiorofacial spasms (Figure 10).

March 7, 1988: Oculinum was injected with good results (Figure 11). I repeated the injections 30 times, with intervals of 3 to 4 months, always with good results. I did not note a reduction of the effect. Only at the 20th injection did blepharoptosis occur, which disappeared after 15 days.

BOTULINUM A TOXIN FOR EYELID INJECTION PROTOCOL

1. PATIENT SELECTION
A. Only patients who would otherwise require eyelid surgery will be considered for toxin injections.
B. 18 - 80 years of age.
C. Informed consent will be obtained after thorough discussion.

11. TOXIN
A. Toxin lot 79-11-1 will be used.
B. Dosage schedule:
$6.25 \times 10^{-5}$ micrograms (initial dose, outpatient)

Figure 8. Protocol for eyelid injection.

\section{祖触}

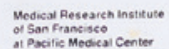

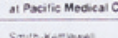

visul scencess

TO: Blepharospasm Investigators (Botulinum Toxin Injection)

FROM: Alan Scott, M.D.

RE : Research To Prevent Blindness Science Writers Seainar

The attached manuscript represents a talk which I will give at the next Science Writers Seminar which is sponsored by Research To Prevent Blindness, October 2, 1984 .

Your names and addresses will be made available to prospective patients who contact either our office or The Benign Essential Blepharospasm Foundation in Beaumont, Texas.

Figure 9. A letter from Alan Scott to the blepharospasm Investigators (Botulinum Toxin Injection) telling me that my name and address would be available to prospective patients after the talk he would give at the Science Writers Seminar, which was sponsored by Research to Prevent Blindness in October 1984

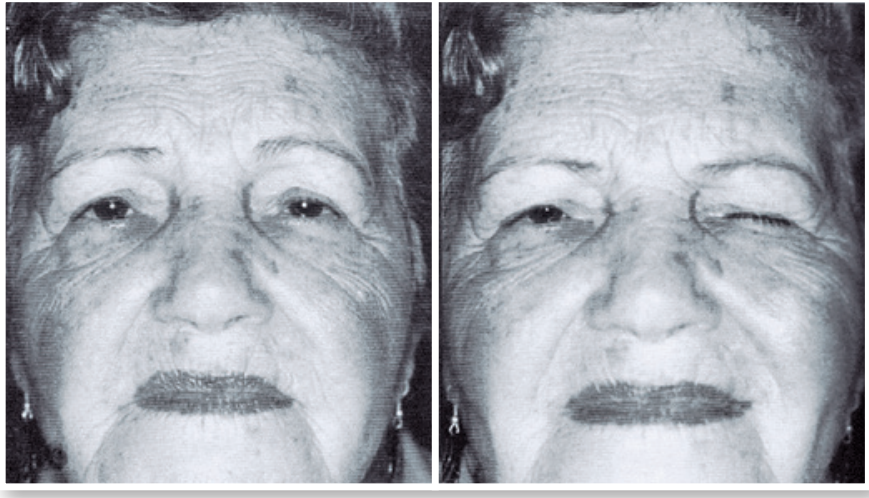

Figure 10. Patient with left eyelid spasm before and after Botox injection

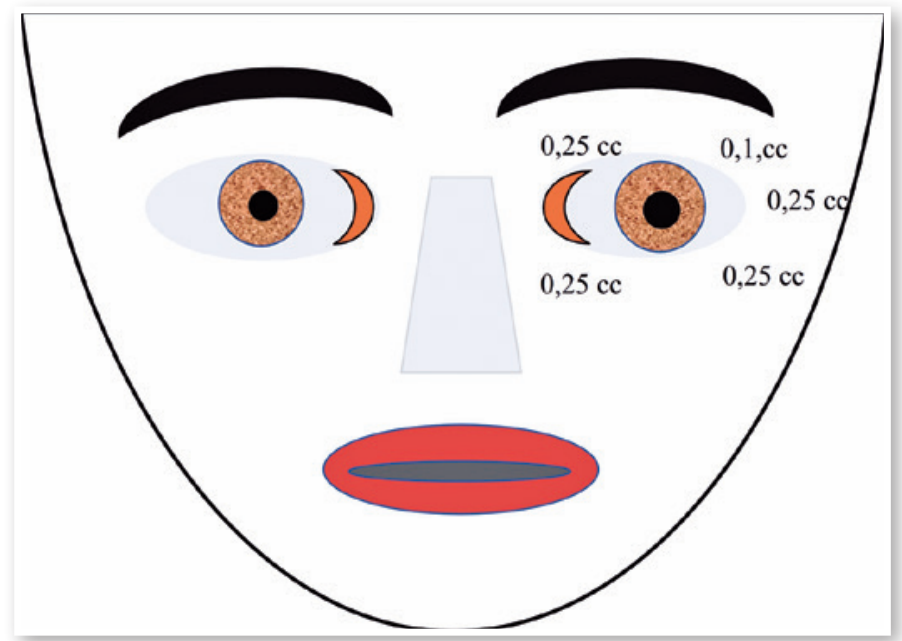

Figure 11. Drawing to show the places and doses of Botox injections for treating blepharospasm.

\section{CASE 5}

October 28, 1992: M.A.C., female; closed eyes; jerking of the face, mouth, and neck; dysphonia (Figure 12). The patient was taking clonazepam.

Diagnosis: Orofacial dystonia (Meige's syndrome)

Oculinum was injected bilaterally (Figure 13) in her face, mouth, and neck. The result was satisfactory; I repeated the injections 16 times with intervals of about 4 months. 1 did not observe a reduction in the effect.

\section{CASE 6}

February 28, 1982: Over the past 16 years, the patient's left eye had been closing. The patient could not see out of this eye.

Diagnosis: Left eye lid blepharospasm (Figure 14). 


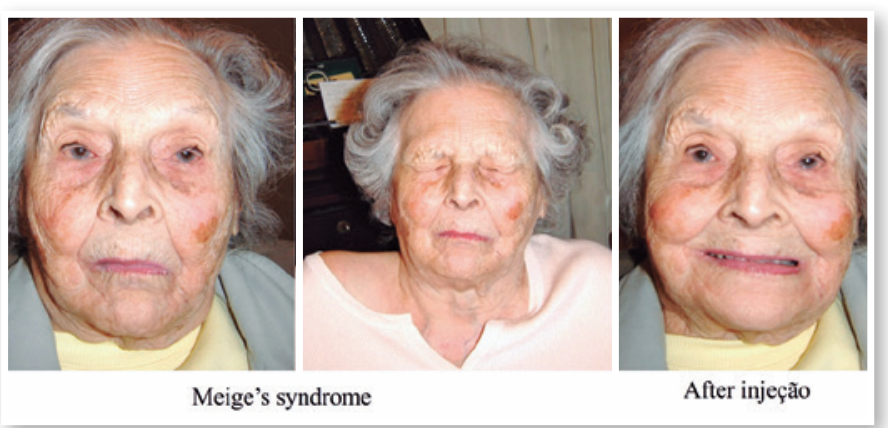

Figure 12. Patient with Meige's syndrome before and after Botox injection.

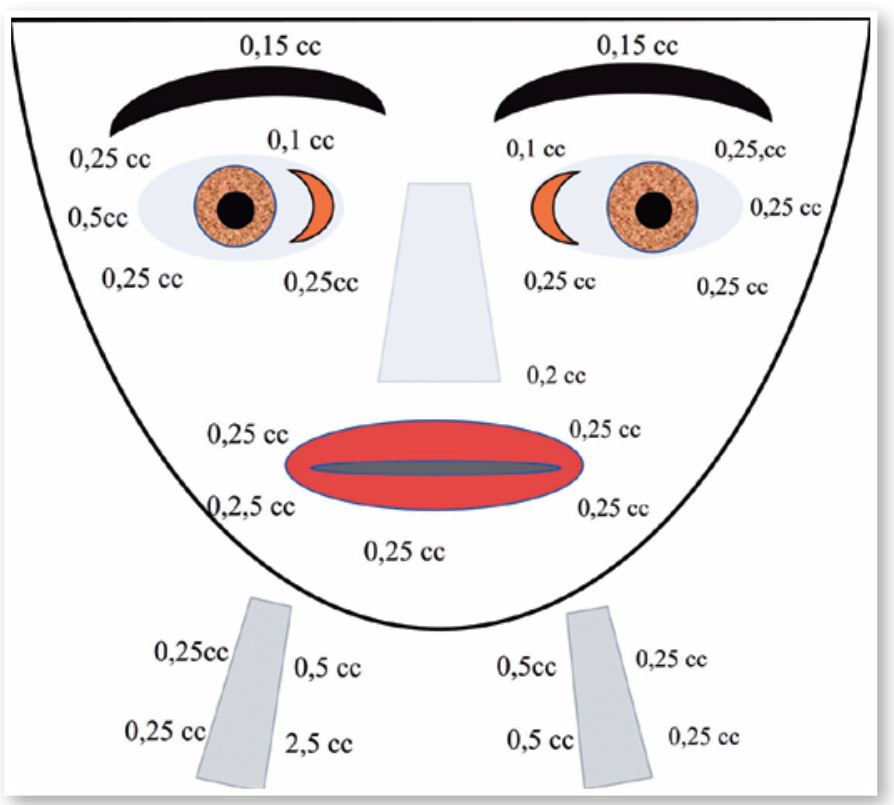

Figure 13. Doses and placement of Botox injections in the patient shown in Fgure 12.
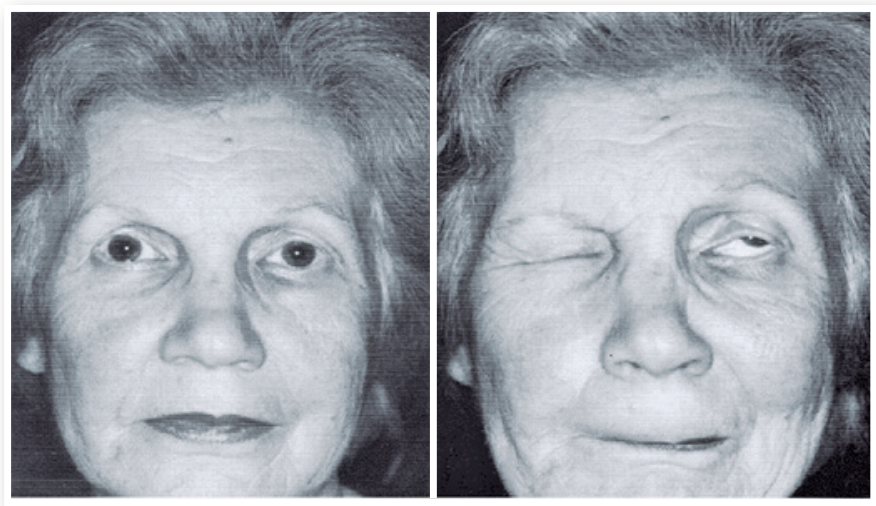

Figure 14. Patient with right blepharospasm. Right: interval between spasms.

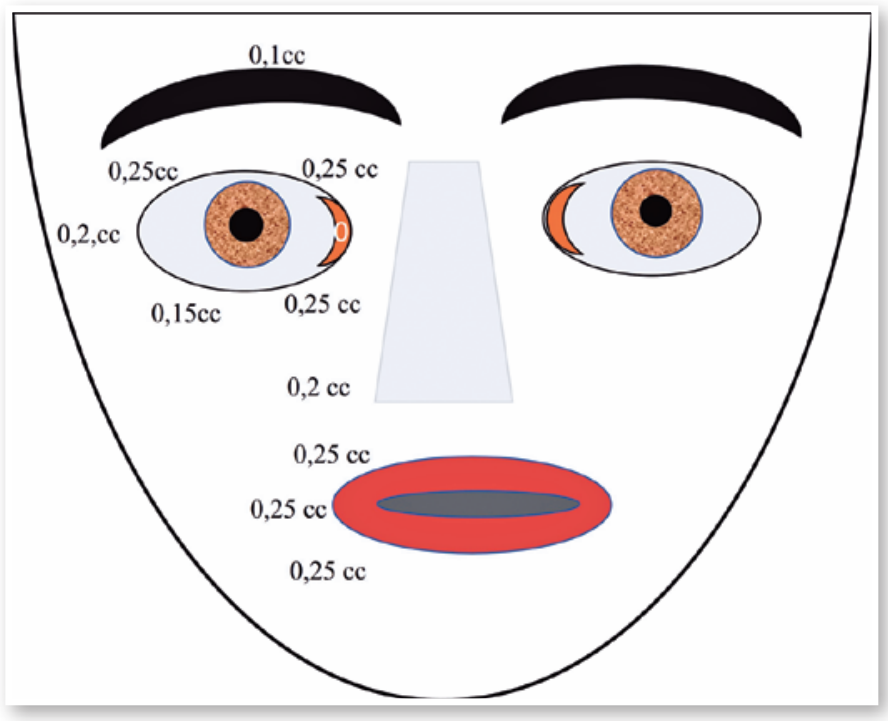

Figure 15. Places of injections and doses of Botox in the patient show in Figure 14.

Botox was injected around her left eye 21 times, with intervals of 3 to 4 months until 1999 (Figure 15). In 1998, I went to use Botox. I did not observe a reduction in the effect.

In the old days, treatment for strabismus in Brazil could be summarized as orthoptic, pleoptic, and surgery, until the day when I began to use botulinum toxin, which I brought to Brazil in 1981. Facial and palpebral dystonias were treated pharmacologically. Colleagues of the Escola Paulista de Medicina tried to use baclopheno ${ }^{(4,5)}$, but with meager results. Things have changed for physicians and their patients all around the world, thanks to the beautiful work of Alan B. Scott and Brazilian researchers with my initial work with Oculinum/Botox.

\section{REFERENCES}

1. Scott $A B$, Collins CC. Division of labor in human extraocular muscle. Arch Ophthalmol. 1973;90(4):319-22.

2. Scott AB. Botulinun toxin injection of eye muscles to correct strabismus. Trans Am Ophthalmol Soc. 1981;79:734-70.

3. Scott AB. Botulinun toxin treatment of strabismus and blepharospasm: a multiple investigator study. In: Campos E, (ed). International Strabismological Association (ISA). Proceedings of the Fifth Meeting. Modena, Italy, Athena Scientific ; 1986.

4. Cunha MC, Aguirre OP, Souza-Dias CR. Tratamento do espasmo facial unilateral com toxina botulínica tipo A. Arq Bras Oftalmol. 1998;61(1):54-60.

5. Andrade LA, Bertolucci PH. Tratamento da doença de Meige com droga agonista de receptores GABA. Arch Neoropsiquiatr. 1985;43(3):260-6. 